\title{
Duodenal darlık Helicobacter pylori eradikasyonu ile gerileyebilir mi?
}

\author{
Can duodenal stenosis decrease with Helicobacter pylori eradication?
}

\author{
Bilge BAŞ \\ Antalya Eğitim ve Araştırma Hastanesi, Gastroenteroloji Kliniği, Antalya
}

\begin{abstract}
Giriş ve Amaç: Helicobacter pylori mide mukozasında kolonize olarak dispepsi, ülser, mide kanseri ve ülserin bir komplikasyonu olarak post-bulber darlığa neden olabilir. Bu makalede Helicobacter pylori'ye bağlı post-bulber darlık gelişmiş hastalarda eradikasyon ile elde edilen sonuçlar tartışılmıştır. Gereç ve Yöntem: Ortalama yaşları 42.8 yıl olan, endoskopi ile post-bulber darlik ve Helicobacter pylori saptanan 145 hastanın sonuçları retrospektif incelenmiştir. Mide tümörü, peptik ülser ve Helicobacter pylori negatif olan hastalar çalışmaya alınmamıştır. Tedavi öncesi ve sonrası kusma, karın ağrısı ve endoskopi sonuçları değerlendirilmiştir. Birinci basamak tedavi olarak lansoprazol, amoksisilin, klaritromisin; bu tedavi ile başarı sağlanamazsa lansoprazol, bizmut, tetrasiklin ve metronidazol kullanılmıştır. Bulgular: Tedavi öncesi kusma oranı \%92.8 iken Helicobacter pylori eradikasyonu sağlananlarda \%19'a gerilemiştir ( $p$ <0.01). Bu hastaların sadece \%52'sinde endoskopik olarak geçiş sağlanmıştır ( $p>0.05)$. Karın ağrısı tedavi öncesinde $\% 58.7$ iken; tedavi sonrasında \%12.3'tür ( $p<0.01)$. Karın ağrısı geçen hastaların \%45'inde endoskopik geçiş izlenmiştir ( $p>0.05$ ). Helicobacter pylori eradikasyonu sağlanamayanlarda kusma \%38.3'e gerilemiştir $(p<0.05)$. Helicobacter pylori eradikasyonu ve endoskopik olarak geçiş sağlanan hastaların hepsinde kusma ve karın ağrısı geçmiştir. Endoskopik geçiş sağlanamayan 69 hastanın 38'inde Helicobacter pylori enfeksiyonu devam ettiği için ikinci eradikasyon tedavisi verilmiştir. 38 hastanın 14'ünde eradikasyon başarılı olmuştur ve geçiş sağlanmıştır. Helicobacter pylori eradikasyonuna rağmen obstrüksiyonu devam eden 24 hasta endoskopik ve cerrahi diğer yöntemlerle tedavi edilmiştir. Sonuç: Başarill Helicobacter pylori eradikasyonunun hem klinik hem de endoskopik darlık üzerine olumlu etkisi vardır. Hatta endoskopik geçiş sağlanamasa da Helicobacter pylori yoğunluğuyla beraber enflamasyon ve ödemin azalmasılla kusma, karın ağrısı şikayetlerinde düzelme olmaktadır.
\end{abstract}

Anahtar kelimeler: Duodenal darlık, Helicobacter pylori, peptik ülser hastalığı

\section{GiRiş}

Peptik ülser hastalığı, Helicobacter pylori (Hp) enfeksiyonu dışında nonsteroid antiinflamatuvar ilaç (NSAii) kullanımı ve strese bağlı mukozal hasar nedeniyle oluşabilmesine rağmen $H p$ enfeksiyonu ile duodenal ülser arasında direkt bağlantı olduğu bilinmektedir (1). Enfeksiyonun dünyada gelişmiş ülkelerde prevalansı \%20-50 iken, gelişmekte olan ülkelerde bu oran neredeyse \%80'dir (2). İnsandan insana bulaşın oral-oral, gastrik-oral, fekal-oral yollarla gerçekleştiği bildirilmiştir. Özellikle gelişmekte olan ülke-

\footnotetext{
Iletişim: Bilge BAŞ

Antalya Eğitim ve Araştırma Hastanesi, Gastroenteroloji Kliniği, Antalya

Faks: +902422494487

E-mail: bilgeormeci@hotmail.com
}

Background and Aims: Helicobacter pylori bacteria reside in the gastric mucosa and cause dyspepsia, ulcer, gastric carcinoma, and post-bulbar stenosis. We discussed the outcomes of Helicobacter pylori eradication in patients with post-bulbar stenosis due to Helicobacter pylori. Materials and Methods: The results of 145 patients with a mean age of 42.8 years and having post-bulbar stricture and Helicobacter pylori were retrospectively analyzed. Patients with gastric tumor and peptic ulcer and those negative for Helicobacter pylori were excluded. Vomiting, pain, and endoscopy access were evaluated before and after treatment. Lansoprazole, amoxicillin, and clarithromycin were used as first-line therapy. If these treatments failed, lansoprazole, bismuth, tetracycline, and metronidazole were used. Results: The pretreatment vomiting rate was $92 \%$, and the Helicobacter pylori eradication rate decreased to $19 \%(p<0.01)$. Endoscopic access was achieved in only $52 \%$ of the patients $(p>0.05)$. Abdominal pain was observed in $58.7 \%$ patients before treatment and in $12.3 \%$ patients after treatment ( $p<$ 0.01). Endoscopic transition was observed in $45 \%$ patients with cured abdominal pain ( $p>0.05$ ). The vomiting rate was reduced to $38.3 \%$ in patients who could not undergo Helicobacter pylori eradication ( $p<$ 0.05). All the patients with Helicobacter pylori eradication and endoscopic transition experienced no vomiting or abdominal pain. Twenty-four patients with obstruction despite Helicobacter pylori eradication were treated with endoscopic and other surgical methods. Conclusions: Successful Helicobacter pylori eradication has a positive effect on both clinical outcomes and endoscopic strictures. Although an endoscopic transition cannot be achieved, there is an improvement in vomiting and abdominal pain complaints due to the decrease in inflammation and edema associated with Helicobacter pylori density.

Key words: Duodenal stenosis, Helicobacter pylori, peptic ulcer disease

lerde aile içi geçişin öneminden bahsedilmektedir (3). Kliniğinde akut enfeksiyonda bulantı, kusma ishal gibi özgül olmayan belirtiler, kronik enfeksiyonda ise epigastrik ağrı, dispeptik semptomlar, ağız kokusu, bulantı, kusma gibi belirtiler görülmektedir (1). Hp'ye bağlı oluşan duodenal ülser inflamasyon ve fibrozise neden olarak kronik hastalığın sık rastlanılan komplikasyonu olan ülser bölgesinde oluşan darlık oluşturur (4). Duodenal darlık; Hp'ye bağlı duodenal ülser hastalığı dışında gastrointestinal motilite

Baş B. Can duodenal stenosis decrease with Helicobacter pylori eradication? The Turkish Journal of Academic Gastroenterology 2019;18:12-15. DOI: 10.17941 /agd.546526

$$
\text { Geliş Tarihi: 24.09.2018 • Kabul Tarihi: 19.12.2018 }
$$


bozuklukları, polip, divertikül, volvulus, Crohn hastalığı, tüberküloz, bezoar, neoplazi gibi nedenlere bağlı olarak da oluşabilmektedir (5). Hp eradikasyon tedavisi, duodenal darlığın fibrozis ve ödem ile daha fazla provoke olmasını engeller, bu nedenle tedavide ilk yaklaşım Hp eradikasyonudur. Bu tedaviye cevap vermeyen olgularda endoskopik balon dilatasyonu ve/veya cerrahi düşünülmelidir (6). Hp Enfeksiyonu ile duodenal ülser arasındaki ilişki bilinmesine rağmen eradikasyon tedavisinin ülsere bağlı oluşan mide çıkış darlı̆ı üzerine ne kadar etkili olacağı bilinmemektedir. Bu çalışmada Helicobacter pylori eradikasyon tedavisinin mide çıkış darlığının klinik ve endoskopik bulguları üzerine etkisi araştıııldı.

\section{GEREÇ ve YÖNTEM}

Çalışmaya 5 yıl süresince üst gastrointestinal sistem (GiS) endoskopisi yapılan ve endoskopik olarak gastrik çıkış obstrüksiyonu (post-bulber, pilor ya da duodenal darlığı) saptanan ve patolojik olarak Hp pozitif olan 145 hasta alındı. Aktif GiS kanama geçiren, özofagus darlığı ve tümörü, mide ya da duodenum ülseri olan, malignite şüphesi bulunan ya da biyopsi sonucu malignite gelen hastalar, Hp negatif hastalar ile Hp eradikasyon tedavisi aldığı bilinen hastalar çalışmaya alınmadı. Bu ölçütlerin dışında kalan 18 yaş üstü hastaların sonuçları geriye dönük olarak incelendi. Her olgu tedavi öncesi ve sonrası obstrüksiyon semptomları (kusma, karın ağrısı), endoskopi sonuçları ve $H p$ eradikasyonuna göre incelendi. Hastaların üst GiS endoskopi raporları taranarak yaş, cinsiyet bilgileri kaydedildi. Gastroskopi ile darlık saptanan hastalarda antrum ve korpustan alınan biyopsi örneği $H p$ açısından histopatolojik olarak değerlendirildi. Hp varlığı patoloji laboratuvarında biyopsi materyalinin modifiye "Giemsa" yöntemiyle boyanarak ışık mikroskopunda değerlendirilmesiyle saptandı. Birinci basamak tedavi olarak lansoprazol 2x30 mg/gün, amoksisilin 2x1000 mg/gün, klaritro- misin $2 \times 500$ mg/gün 14 gün süreyle uygulandı. Bu tedavi ile başarı sağlanamayan olgulara lansoprazol $2 \times 30 \mathrm{mg}$, ranitidin bizmut sitrat $2 \times 400 \mathrm{mg}$, tetrasiklin $4 \times 500 \mathrm{mg}$ ve metronidazolden $3 \times 500 \mathrm{mg}$ oluşan dörtlü tedavi verildi.

Bu gruplamalara göre değerlendirilen verilerle ilk önce "SPSS for Windows 16.0" programılla sıklık istatistikleri uygulandı, grup karşılaştırmaları ki-kare ve Student-t testi ile yapıldı.

\section{BULGULAR}

Çalışmaya ortalama yaşları $42.8 \pm 14.5$ yıl olan 145 hasta dahil edildi. Hp pozitif 145 hastanın 83'ünde (\%57.2) birinci basamak tedaviyle $H p$ eradike edildi ve bu hastaların endoskopik kontrollerinde 38'inde post-bulber darlığın devam ettiği görüldü. Buna karşın kusma sadece 28 hastada ve karın ağrısı sadece 18 hastada $(p<0.05)$ devam etti. Hp eradikasyonu sağlanamayan 62 hastanın 11 'inde eradikasyon başarılı olmamasına rağmen post-bulber geçiş sağlandı. Yine bu grup hastada kusma ve karın ağrısı anlamlı olarak azaldı. Illk tedavi ile başarılı olamayan hastalarda dörtlü tedavi denendi ve sonuçta 145 hastanın 62 'sinde $H p$ pozitifliği devam etmesine rağmen 48 'inde endoskopik olarak darlığın devam ettiği görüldü. Mide çıkış obstrüksiyonu devam eden 48 hastanın endoskopisinde ödem azalmış görülmekle birlikte geçiş sağlanamadı ve 30'unda $H p$ enfeksiyonunun devam ettiği saptandı. $H p$ eradike edilmesine rağmen mide çıkış obstrüksiyonu devam eden 48 hasta endoskopik dilatasyon veya cerrahi yöntemler ile tedavi edildi (Tablo 1, Grafik1).

\section{TARTIŞMA}

Peptik ülser etyopatogenezinde multifaktöriyel nedenlerin suçlandığı bir hastalıktır. Hp ile birlikteliği ve $H p^{\prime}$ nin ülser üzerine etkisi konusunda güçlü yayınlar mevcuttur. Yüksek $H p$ prevalansı olan ülkelerde peptik ülser ve

Tablo 1. Helicobacter pylori eradikasyonuna göre tedavi öncesi ve sonrası karın ağrısı şikayeti değişimi

\begin{tabular}{|c|c|c|c|c|c|c|c|c|}
\hline & \multicolumn{2}{|c|}{ Hp } & \multicolumn{2}{|c|}{ Kusma } & \multicolumn{2}{|c|}{ Karın Ağrısı } & \multicolumn{2}{|c|}{ Post-bulber Darlık } \\
\hline \multirow[b]{2}{*}{ Tedavi öncesi } & $\mathbf{n}$ & $\%$ & $\mathbf{n}$ & $\%$ & $\mathbf{n}$ & $\%$ & $\mathbf{n}$ & $\%$ \\
\hline & 145 & 100 & 145 & 100 & 126 & 86,8 & 145 & 100 \\
\hline ¿ & 83 & 57,2 & 28 & 19 & 18 & 12,3 & 38 & 48 \\
\hline ־ & 62 & 42,8 & 35 & 24,13 & 38 & 26,2 & 51 & 52 \\
\hline \multirow{2}{*}{ 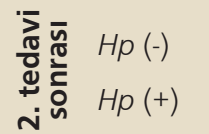 } & 32 & 22,06 & 15 & 10,3 & 12 & 8,2 & 24 & 16,5 \\
\hline & 30 & 20,74 & 14 & 9,6 & 14 & 9,6 & 24 & 9,6 \\
\hline
\end{tabular}




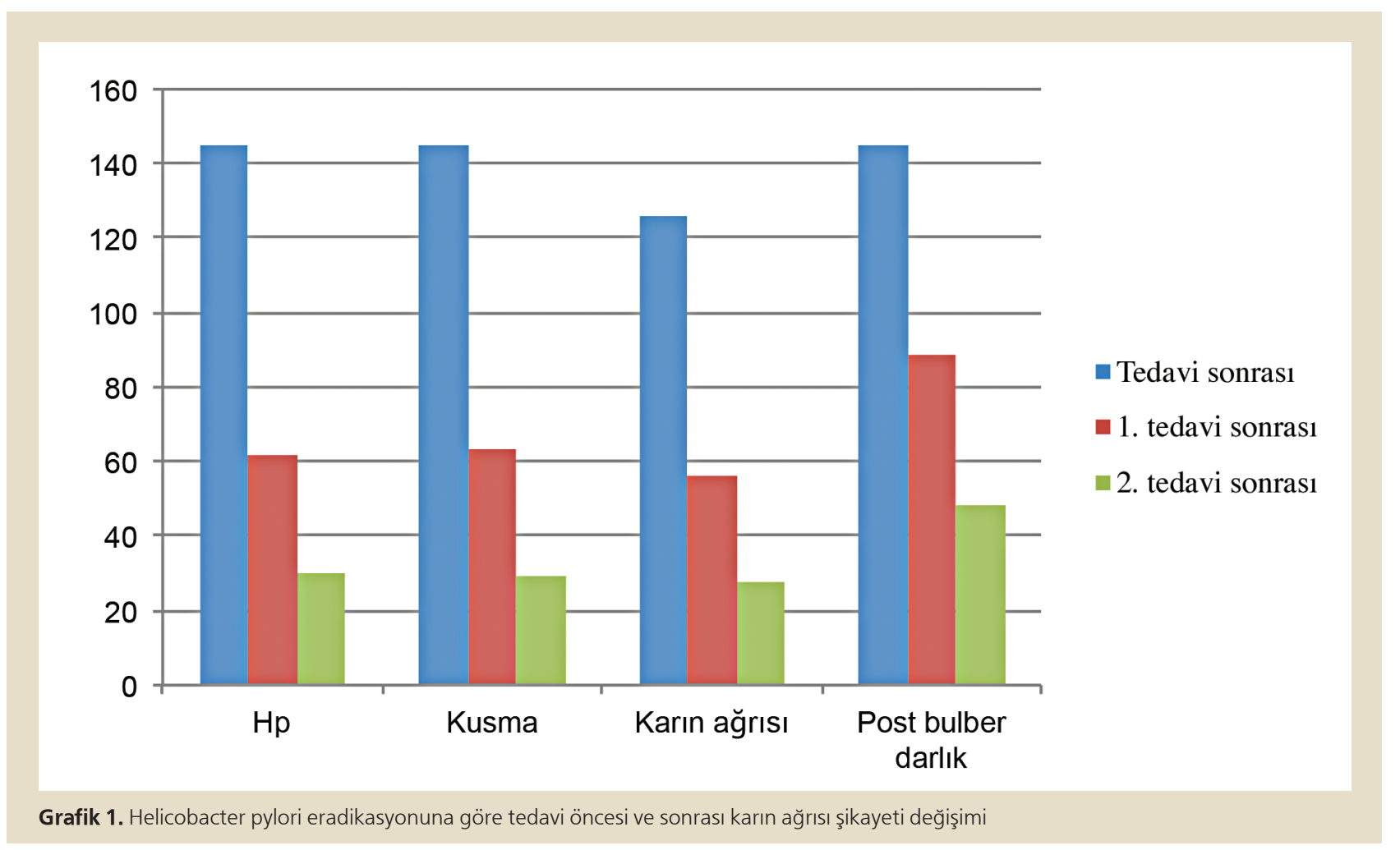

komplikasyonları da yüksek bulunmuştur (7). Hp eradikasyonu gastritin inflamatuvar aktivitesini ve kronik gastriti iyileştirmektedir (8). Uzun yıllar devam eden duodenal ülserin komplikasyonları da yıllar içinde gelişmektedir. Benign mide çıkış darlığı peptik ülser vakalarının sadece \%3'ünde görülen en nadir komplikasyonlardandır (9). Ancak duodenal ülserlerin olduğu gibi post-bulber darlığın da \%94'üne yakınına $H p$ neden olmaktadır (10). Ek olarak aşırı NSAil kullanımı da primer veya sekonder olarak peptik ülser gelişimi etkileyebilir. Benign duodenal darlığın güncel tedavisi proton pompa inhibitörleri, sukralfat, NSAil'ların kesilmesi ve Hp eradikasyon tedavisidir. Son zamanlardaki araştırmalar benign duodenal darlık tedavisinde endoskopik balon dilatasyonu ile medikal tedavinin ilk basamak tedavisi olarak kabul edildiğini göstermiştir (11), ancak hastaların üçte birinde önünde sonunda cerrahi müdahale gerekecektir. Bu çalışmada NSAil kullanımı olan ve Hp negatif bulunan hastalar çalışma dışı bırakıldığı için bu durumlarla ilgili bir karşılaştırma yapılamamışır. $H p$ eradikasyonu için birinci basamak tedavi 14 gün süreyle uygulanmıştır, bu tedavi protokolü Amerikan Gıda ve Illaç Dairesi (FDA) tarafından onaylanan tedaviler arasında yer almakta olup, 10 günlük tedavide $\% 81-84,14$ günlük tedavide ise \%83-92 gibi eradikasyon oranları verilmiştir (12). Ancak ülkemizde yapılan 3'lü tedavi protokolleri ile ilgili bazı çalışmalarda Hp tedavi başarısı direnç nedeniyle oldukça düşük oranlarda bulunmuştur. Bir haftalık tedavi ile $H p$ eradikasyon oranı bir çalışmada \%46 bulunmuştur. İki hafta uygulanan üçlü tedavi ile bu oran \%50-65 arasındadır (13). Bu çalışmada da ilk basamak tedavi ile eradikasyon sağlanamayan hastalarımız olmuştur. Hp enfeksiyonu tedavisindeki başarısızlıkta pek çok faktörün rol oynadığı bilinmektedir. Bunların en önemlisi kuşkusuz antibiyotik direncidir. Ayrıca hasta uyumu, tedavi süresinin uzun olması bu başarısızlıkta rol oynayan faktörlerdir. Ancak hastalarımızda istatistiksel olarak anlamlı bir oranda Hp'nin eradike edilememesine hatta duodenal darlğın devam etmesine rağmen bulantı, kusma, karın ağrısı şikayetlerinde azalma olmuştur. Bu da Hp'ye bağlı olan enflamasyonun azalması ile birlikte ödemin çözülmesi ile ilişkili olarak düşünülmüştür. Bu grup hastalarda 14 gün sürecek ikinci basamak tedavisine geçilmiştir. Bizmutun da ilave edildiği dörtlü tedavi uygulanmıştır. Üçlü tedavi ile karşılaştırıldığında $H p$ eradikasyon başarısı daha kuvvetli olan bu dörtlü tedavi ile hastalarımızın bir kısmında daha eradikasyon başarısı elde dilmiştir. Ülkemizde yapılan tedavi protokollerini karşılaştıran bir çalışmayla bu sonuç desteklenmektedir (13). Burada hem tedavinin üstünlüğü hem de uzamış tedavi süresi etkili olmuş olabilir. Ancak tüm bu tedavilere rağmen başarılı olamadığımız ve duodenal obstrüksiyonu geçemediğimiz vakalarda endoskopik ve/veya cerrahi yöntemlere başvurulmuştur. 
Çalışmaya Hp negatif olan ve sadece PPI tedavisi verilen hastaların alınmaması ve bir karşılaştırma yapılmaması bu çalışmanın zayıf yönü olarak belirtilebilir. Bu vakaların da olduğu karşılaştırma grubunun dahil edilmesi ile çalışmanın gücü artııabilirdi. Ayrıca prospektif olarak $\mathrm{Hp}$ pozitif hastalarda sadece PPI ve eradikasyon tedavisi ile beraber PPI tedavisinin karşılaştırılması ile eradikasyon tedavisinin etkinliği daha güvenilir olarak belirlenebilir.

Hp eradikasyonu mide çıkış obstrüksiyonuna bağlı kusma, karın ağrısı şikayetlerinde endoskopik olarak geçiş

\section{KAYNAKLAR}

1. Ruggiero P. Helicobacter pylori and inflammation. Curr Pharm Des 2010;16:4225-36.

2. Narayanan M, Reddy KM, Marsicano E. Peptic ulcer disease and Helicobacter pylori infection. Mo Med 2018;115:219-24.

3. Napolitano L. Refractory peptic ulcer disease. Gastroenterol Clin North Am 2009;38:267-88.

4. Yeo $\mathrm{SH}$, Yang $\mathrm{CH}$. Peptic ulcer disease associated with Helicobacter pylori infection. Korean J Gastroenterol 2016;67:289-99.

5. Gisbert JP, Pajares JM. Helicobacter pylori infection and gastric outlet obstruction-prevalence of the infection and role of antimicrobial treatment. Aliment Pharmacol Ther 2002;16:1203-8.

6. Cherian PT, Cherian S, Singh P. Long-term follow-up of patients with gastric outlet obstruction related to peptic ulcer disease treated with endoscopic balloon dilatation and drug therapy. Gastrointest Endosc 2007;66:491-7.

7. Malfertheiner P, Megraud F, O'Morain C, et al. Current concepts in the management of Helicobacter pylori infection: the Maastricht III Consensus Report. Gut 2007;56:772-81.

8. Pilotto A, Perri F, Leandro G, Franceschi M; Aging and Acid-Related Disease Study Group. Effect of Helicobacter pylori eradication on the outcome of reflux esophagitis and chronic gastritis in the elderly. A randomized, multicenter, eight-month study. Gerontology 2006;52:99-106. sağlanamasa dahi azalmaya neden olmaktadır. Semptomlarda azalma olması Hp yoğunluğunun azalmasına bağlı olarak o bölgedeki enflamasyon ve ödemin azalması ile ilgili olabileceği şeklinde yorumlanmıştır. Sonuç olarak epigastrik bölgede lokalize karın ağrısı ve beraberinde kusma şikayeti bulunan hastalarda Hp enfeksiyonu ve onun bir komplikasyonu olan duodenal darlık ayırıcı tanıda mutlaka düşünülmelidir. Başarılı Hp eradikasyonu hem obstrüksiyon semptomları hem de endoskopik darlık üzerine olumlu etkilidir denebilir.
9. Wang YR, Richter JE, Dempsey DT. Trends and outcomes of hospitalizations for peptic ulcer disease in the United States, 1993 to 2006. Ann Surg 2010;251:51-8.

10. Appasani S, Kochhar S, Nagi B, et al. Benign gastric outlet obstruction-spectrum and management. Trop Gastroenterol 2012;32:25966.

11. Hamzaoui L, Bouassida M, Ben Mansour I, et al. Balloon dilatation in patients with gastric outlet obstruction related to peptic ulcer disease. Arab J Gastroenterol 2015;16:121-4.

12. Selgrad M, Kandulski A, Malfertheiner P. Helicobacter pylori: diagnosis and treatment. Curr Opin Gastroenterol 2009;25:549-56.

13. Uygun A, Tüzün A, Yeşilova Z, et al. Helicobacter pilori eradikasyon tedavisinde 7 ve 14 günlük lansoprazol, klaritromisin, amoksisilin protokolünün karşılaştırılması. Akademik Gastroenteroloji Dergisi 2005;4:172-5. 